\title{
Renal Denervation: Unde Venis et Quo Vadis?
}

\section{Renale Denervation: Unde venis et quo vadis?}

Authors

Affiliations
C. P. Nähle ${ }^{1}$, R. Düsing ${ }^{2}$, H. Schild ${ }^{1}$

1 Department of Radiology, University of Bonn, Germany

Hypertoniezentrum Bonn, Schwerpunktpraxis Kardiologie-Angiologie-Rehabilitation, Bonn, Germany
Key words

- hypertension

- radiofrequency (RF) ablation

- renal arteries

safety

received $\quad 1.9 .2014$

accepted $\quad 13.9 .2014$

Bibliography

DOI http://dx.doi.org/

10.1055/s-0034-1385526

Published online: 28.1.2015

Fortschr Röntgenstr 2015; 187:

237-247 @ Georg Thieme

Verlag KG Stuttgart · New York .

ISSN 1438-9029

\section{Correspondence \\ Dr. Claas Philip Nähle}

Department of Radiology,

University of Bonn

Sigmund-Freud-Str. 25

53105 Bonn

Germany

Tel.: ++49/1 78/8029019

Fax: ++49/2 87/57 60

Claas.Naehle@ukb.uni-bonn.de

\section{Abstract}

$\nabla$

Objective and Methods: Renal denervation is a minimally invasive, catheter-based option for the treatment of refractory hypertension. Indications and contraindications for renal denervation have been defined in an interdisciplinary manner. The efficacy and safety of the procedure were evaluated.

Results: Currently, indication for renal denervation is limited to patients with primary hypertension and a systolic blood pressure of $\geq 160 \mathrm{~mm} \mathrm{Hg}$ (or $\geq 150 \mathrm{~mm} \mathrm{Hg}$ in diabetes type 2) despite optimal medical therapy with $\geq 3$ different antihypertensive drugs. In this specific patient population, an average blood pressure reduction of $32 / 14 \mathrm{mmHg}$ was observed in non-randomized/-controlled trials after renal denervation. These results were not confirmed in the first randomized controlled trial with a non-significantly superior blood pressure reduction of $14.1 \pm 23.9 \mathrm{~mm}$ $\mathrm{Hg}$ compared to controls $(-11.74 \pm 25.94 \mathrm{~mm}$ $\mathrm{Hg}$, difference $-2.39 \mathrm{~mm} \mathrm{Hg} \mathrm{p}=0.26$ for superiority with a margin of $5 \mathrm{~mm} \mathrm{Hg}$ ) who underwent a sham procedure.

Conclusion: The efficacy and long-term effects of renal denervation need to be re-evaluated in light of the HTN3 study results. To date, renal denervation should not be performed outside of clinical trials. Future trials should also assess if renal denervation can be performed with sufficient safety and efficacy in patients with hypertension-associated diseases. The use of renal denervation as an alternative therapy (e.g. in patients with drug intolerance) can currently not be advocated. Key points:

- The indication for renal denervation should be assessed in an interdisciplinary fashion and according to current guidelines with a special focus on ruling out secondary causes for arterial hypertension.

- $5-10 \%$ of patients with hypertension suffer from refractory hypertension, but only about $1 \%$ of patients meet the criteria for a renal denervation.

- Renal denervation leads to a significant decrease in office blood pressure; however, the impact on 24-hour blood pressure measurements remains unclear.

- In the first randomized controlled trial on renal denervation with a control group undergoing a sham procedure, blood pressure reduction failed to reach the anticipated level of superiority over best medical treatment.

- Periprocedural complications are rare, but long-term safety can currently not be appraised due to the limited data available.

Citation Format:

- Naehle CP, Düsing R, Schild H. Renale Denervation: Unde venis et quo vadis?. Fortschr Röntgenstr 2015; 187: 237-247

\section{Zusammenfassung \\ $\nabla$}

Zielsetzung und Methode: Die renale Denervation ist eine minimal-invasive, katheterbasierte Behandlungsoption zur Behandlung der therapierefraktären Hypertonie. Die Indikationen und Kontraindikationen wurden interdisziplinär erarbeitet und festgestellt. Effektivität und Sicherheit wurden evaluiert.

Ergebnisse: Derzeit ist die Indikation limitiert auf Patienten mit primärer Hypertonie, die trotz einer optimalen medikamentösen Therapie mit $\geq 3$ unterschiedlichen Antihypertensiva einen systolischen Blutdruck von $\geq 160 \mathrm{~mm} \mathrm{Hg}$ (bzw. $\geq 150 \mathrm{mmHg}$ bei Diabetes Typ 2) aufweisen. Nach renaler Denervation nahm in nicht kontrollierten Studien unter Berücksichtigung die- 
ser Kriterien der Blutdruck um durchschnittlich 32/14 mm Hg ab. Diese Ergebnisse konnten in der ersten randomisierten kontrollierten Studie mit einer im Vergleich zur verblindeten Kontrollgruppe nicht signifikanten Reduktion des systolischen Blutdrucks von 14,1 mmHg nicht bestätigt werden.

Schlussfolgerung: Die Effektivität der renalen Denervation, aber auch die Langzeitsicherheit, müssen unter besonderer Berücksichtigung der HTN-3-Daten neu evaluiert werden. Aktuell sollte die renale Denervation außerhalb klinischer Studien nicht durchgeführt werden. Weitere Studien müssen klären, ob die renale Denervation bei hypertonieassoziierten Erkrankungen mit ausreichender Wirksamkeit und sicher durchgeführt werden kann. Die Anwendung als Alternative zur medikamentösen Therapie z. B. bei Medikamentenunverträglichkeit kann derzeit nicht befürwortet werden.

\section{Background}

\section{Epidemiology}

With approximately 30 million people affected in Germany, arterial hypertension is the most common disease of the cardiovascular system. At the same time, hypertension is the most common cause of fatal cardiovascular events, such as stroke, cardiac insufficiency, or heart attack [1]. This high rate of complications of hypertension requires early diagnosis and treatment to improve the prognosis of these patients. A major challenge here is that hypertension does not have typical symptoms but rather symptoms that are non-specific and slowly progress over time, such as headache in the morning, fatigue and reduced physical endurance. Therefore, the disease is often diagnosed late.

According to the current guidelines, arterial hypertension is present when blood pressure values exceed $140 / 90 \mathrm{mmHg}$ at rest [2]. The large majority of patients can be well controlled with antihypertensive monotherapy or with a combination of two or three antihypertensive substances [3]. According to current guidelines, "resistant" or "therapy-resistant" hypertension is present when blood pressure cannot be normalized $(<140 / 90 \mathrm{mmHg}$ ) despite administration of 3 or more blood pressure-lowering medications (including a diuretic) [2]. These patients are particularly at risk for the above mentioned complications since the risk of a fatal cardiovascular disease doubles in adults between 40 and 70 years old when the systolic blood pressure increases by $20 \mathrm{mmHg}$ or the diastolic blood pressure increases by $10 \mathrm{mmHg}$ [4].

Based on these blood pressure limits, 5-10\% of hypertensive patients in Germany are resistant to treatment [5]. In a large study with over 60,000 patients of whom $12.2 \%$ suffered from treatment-resistant hypertension according to these criteria, the percentage reduced to $7.6 \%$ after an ambulatory blood pressure measurement [6]. In addition to this "office hypertension", inconsistent intake of medication is a further cause of treatment resistance. In a current publication, there was medication non-compliance in approximately one-fourth of patients scheduled to undergo renal denervation [7]. In a retrospective analysis, the percentage of hypertensive patients suitable for renal denervation under the HTN-3 inclusion criteria (see below) was only $0.8 \%$ [8]. However, it must be taken into consideration here that the defined limits for treatment resistance $(>140$ /
$90 \mathrm{mmHg}$ ) differ from the lower blood pressure limits for renal denervation (> $160 \mathrm{mmHg}$ ).

\section{Clinical practice}

With respect to underlying etiology, primary types of hypertension are differentiated from secondary types. While the underlying causes of primary hypertension are largely unclear, diseases of the kidneys, vascular changes (aortic coarctation), sleep disturbances, or changes in hormone metabolism are causes for secondary types of hypertension. A secondary form of hypertension is often present in treatment-resistant hypertension. Therefore, in the case of insufficient response to treatment with medication, office or white coat hypertension (pseudoresistance) [8, 9], unreliable intake of medication $[10,11]$, suboptimal or false medication combination, and secondary types of hypertension must be ruled out as the cause of "treatment-resistant" hypertension.

The indication for renal denervation should be determined in an interdisciplinary manner and with participation of a Hypertension Excellence Center (ESH) or a hypertension specialist certified by the German Hypertension Society $[12,13]$. The diagnostic algorithm for determining diagnosis and thus indication is based on the recommendations of the American Heart Association for the diagnosis, evaluation, and treatment of treatment-resistant hypertension [5] shown as a flowchart in $\bullet$ Fig. 1.

\section{Primary, treatment-resistant hypertension - pathophysiology of renal denervation $\nabla$}

The theoretical, pathophysiological considerations on which the principle of renal denervation is based have already been described in detail elsewhere [14 - 19] and are only briefly summarized here. The efferent sympathetic nerve fibers arise from the sympathetic ganglion of the sympathetic trunk in the thoracolumbar transition region (Th10-L1) and then run in the adventitia of the renal arteries in a reticulated manner into the kidneys ( $\bullet$ Fig. 2, 3) [20, $21]$. The efferent sympathetic fibers activate the renin-angiotensin-aldosterone system that can contribute to increased tubular resorption of sodium with consecutive volume retention via release of renin in the juxtaglomerular apparatus and to hypertension via renal and systemic vasoconstriction (with reduction of renal blood flow) [22-24]. The afferent sensory fibers influence (activated e.g. by increased concentrations of adenosine and nitric oxide or renal ischemia) the central sympathetic nervous system activity in the hypothalmus ( $\bullet$ Fig. 2 ) $[16,18,25]$. In animal experiments it could be demonstrated that increased activity of these afferent fibers results in an increase in blood pressure $[17,26]$. This relationship as shown in animal experiments serves as an explanation for the reduced sympathetic muscle nerve activity after explantation of the diseased kidneys in patients having undergone kidney transplantation [19]. It was therefore postulated that the interaction between the kidneys and sympathetic nervous system (activity) plays an important role in the development and persistence of arterial hypertension also in patients without detectable renal disease $[18,22,27,28]$. Additional negative effects of increased ac- 


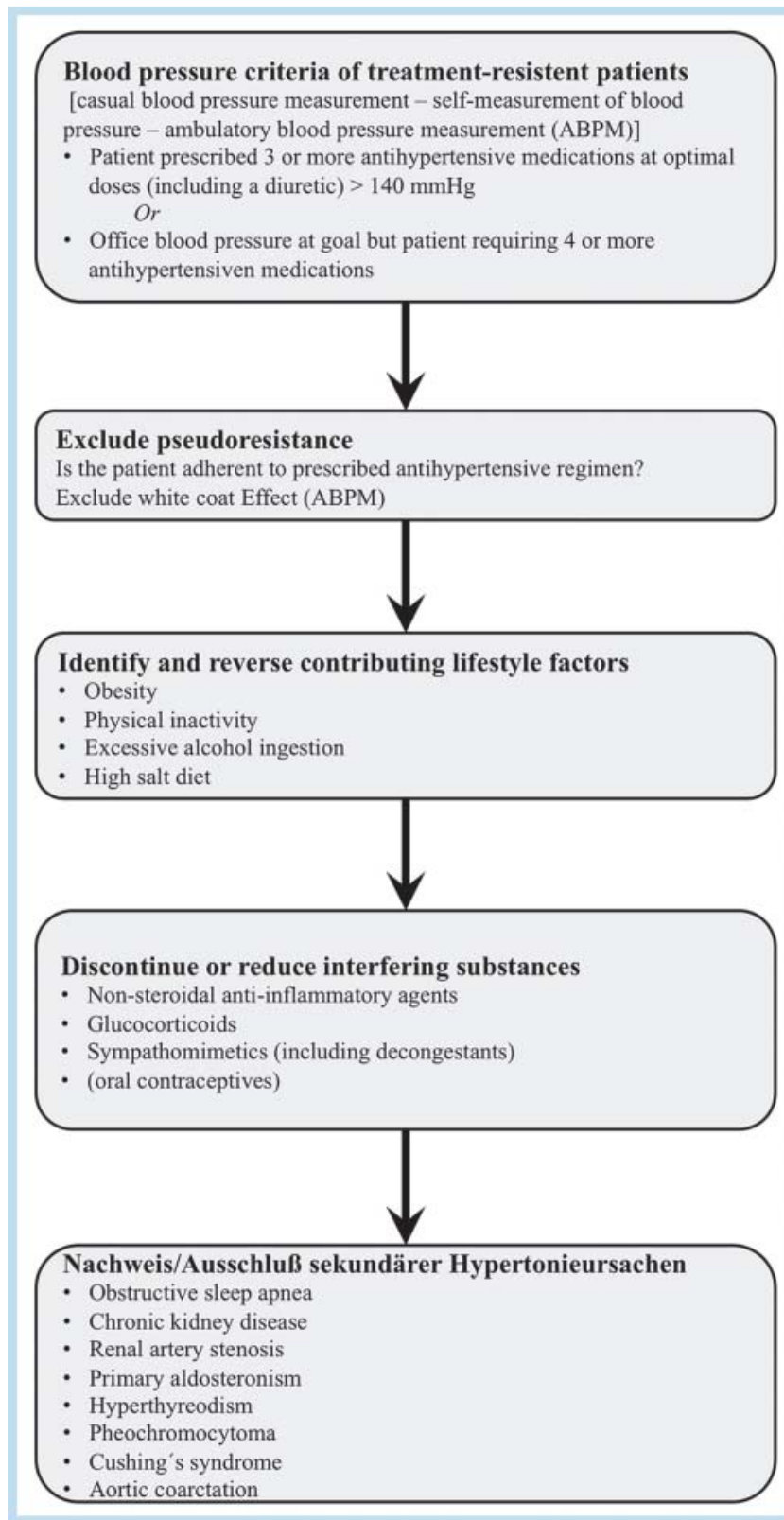

Fig. 1 Algorithm for diagnosis and evaluation of resistant hypertension (adopted from [5]).

tivity of the sympathetic nerve system and renin-angiotensin-aldosterone system include increased gluconeogenesis in the liver, the development of left ventricular hypertension, cardiac ischemia and arrhythmia, and vasoconstriction and enhancement of arteriosclerotic processes in the blood vessels ( $\bullet$ Fig.4) thus promoting the occurrence of hypertensive organ damage and comorbidities [29].

The above-described regulatory circuit is the point of action in renal denervationwhich modulates (reduces) the sympathetic activity or its transmission by thermal damage to the sympathetic nerve fibers [30].

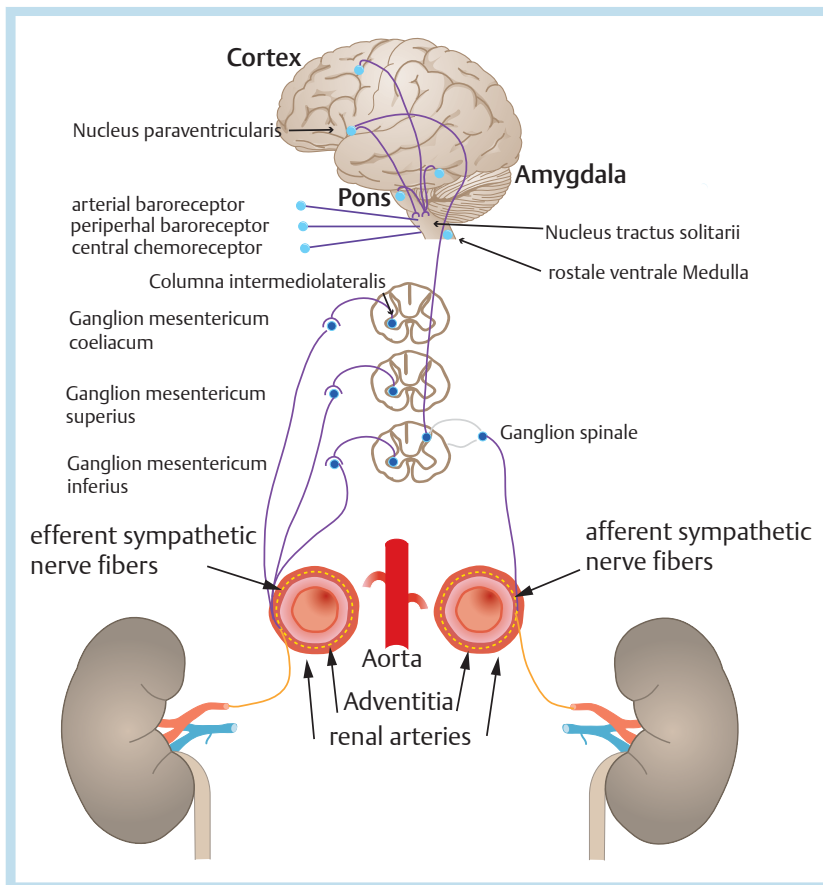

Fig. 2 Physiologic feedback control system of the sympathetic system with focus on renal sympatheticinnervation (adopted from [21]).

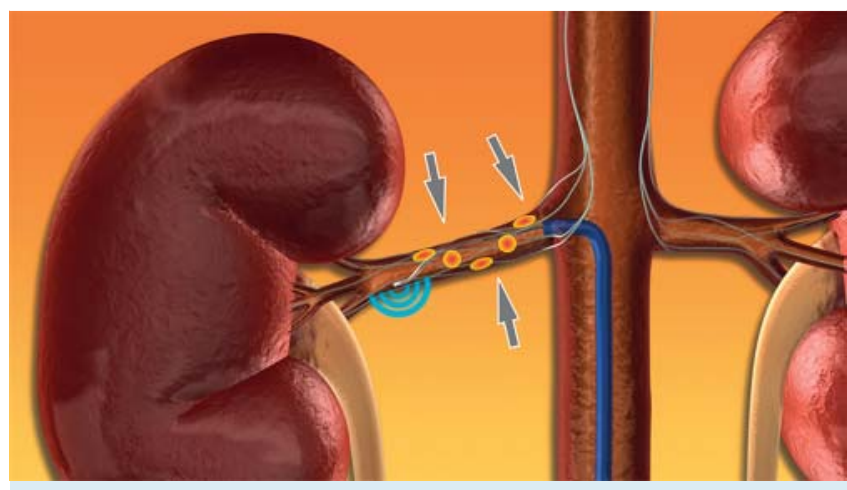

Fig. 3 Schematic representation of renal denervation procedure. Guiding catheter (dark blue) in the right renal artery ostium. Ablation catheter (light gray) with contact to the arterial wall (proximal to first bifurcation) dissipating radiofrequency-induced heating (light blue semicircles). Renal sympathetic nerves (dark gray) located within the renal artery adventitia. Yellow-orange ovals: projected helical path of ablation.

\section{Renal denervation - planning and implementation of the intervention $\nabla$}

Performing preinterventional computed tomography can be helpful for planning the intervention [31] and for ruling out renovascular hypertension [32]. Digital subtraction angiography (DSA) of the aorta is first performed intraprocedurally for orientation purposes to visualize the anatomical relationships [33]. Four catheter systems (Medtronic Ardian, St. Jude Medical EnligHTN, Vessix Vascular V2, Recor Paradise) are currently available in Europe for renal denervation. Covidien stopped distributing the OneShot system at the beginning of 2014 [34]. The anatomical requirements of the different ablation systems and the differences in the structure and application of the ablation catheters are 


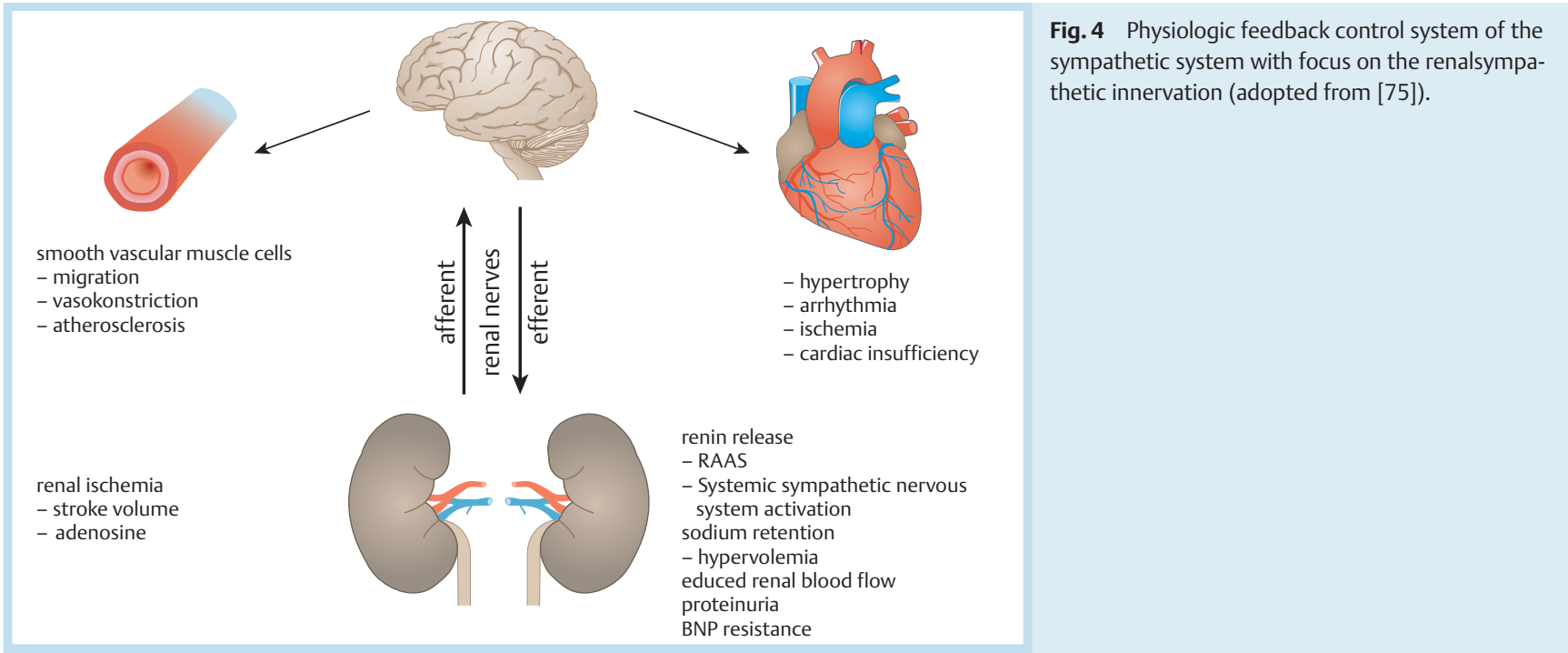

\begin{tabular}{|c|c|c|c|}
\hline $\begin{array}{l}\text { manufacturer| } \\
\text { system }\end{array}$ & type of system & $\begin{array}{l}\text { required } \\
\text { introducer size }\end{array}$ & ablation characteristics \\
\hline $\begin{array}{l}\text { Boston Scienti- } \\
\text { fic Vessix V2 }\end{array}$ & $\begin{array}{l}\text { - balloon-based OTW system } \\
\text { - balloon size must be selected/ } \\
\text { measured (4, 5, } 6 \text { and } 7 \mathrm{~mm} \\
\text { diameter) }\end{array}$ & $8 \mathrm{~F}$ & $\begin{array}{l}\text { - bipolar } \\
\text { - } 4 \text {-8 separate ablation sites } \\
\text { depending on the balloon } \\
\text { diameter } \\
\text { - short ablation time } \\
\text { ( } 30 \text { - } 60 \text { s per side) } \\
\text { - } 1 \text { watt }\end{array}$ \\
\hline $\begin{array}{l}\text { Covidien One } \\
\text { Shot }\end{array}$ & $\begin{array}{l}\text { - balloon-based OTW system } \\
\text { - balloon size must be selected/ } \\
\text { measured ( } 5,6 \text { and } 7 \mathrm{~mm})\end{array}$ & $\begin{array}{l}\text { at least } 7 \mathrm{~F} \text { introdu- } \\
\text { cer ( } 8 \mathrm{~F} \text { for } 7 \mathrm{~mm} \\
\text { balloon diameter) }\end{array}$ & $\begin{array}{l}\text { - unipolar, cooled } \\
\text { - average ablation duration } \\
\text { ( } 2 \text { min. per side) } \\
-25 \mathrm{~W}\end{array}$ \\
\hline $\begin{array}{l}\text { Medtronic } \\
\text { Symplicity }\end{array}$ & $\begin{array}{l}\text { - first catheter generation: Individ- } \\
\text { ual electrode catheter (Symplicity } \\
\text { Flex), not OTW } \\
\text { - current generation: Multi-elec- } \\
\text { trode catheter (Symplicity Spyral), } \\
\text { OTW system } \\
\text { - "one size fits all" }\end{array}$ & $6 F$ & $\begin{array}{l}\text { - unipolar } \\
\text { - ablation duration } \\
\text { ( } 1 \text { min. per side }) \\
\text { - } 6 \text { - } 8 \text { watts }\end{array}$ \\
\hline $\begin{array}{l}\text { St. Jude Medi- } \\
\text { cal EnligHTN }\end{array}$ & $\begin{array}{l}\text { - basket serves as electrode carrier } \\
\text { (not OTW) } \\
\text { - } 2 \text { different sizes ( } 6 \text { and } 8 \mathrm{~mm} \text { ) }\end{array}$ & $8 \mathrm{~F}$ & $\begin{array}{l}\text { - unipolar } \\
\text { - ablation duration } \\
\text { ( } 2 \text { min. per side) }\end{array}$ \\
\hline $\begin{array}{l}\text { ReCor Medical } \\
\text { Paradise }\end{array}$ & $\begin{array}{l}\text { - self-centering balloon-catheter } \\
\text { with central ultrasound probe }\end{array}$ & $7 F$ & $\begin{array}{l}\text { - ultrasound-based ablation } \\
\text { - ablation duration } \\
\text { ( } 2 \text { min. per side) }\end{array}$ \\
\hline
\end{tabular}

Table 1 Comparative overview of CE-marked systems for renal denervation, OTW = over-thewire. shown in 0 Table 1. To be able to ablate a sufficient portion of the sympathetic nerve fibers, a minimum length of the renal artery of approx. $20 \mathrm{~mm}$ to the first bifurcation is needed. First study results indicate that renal denervation with ablation of the dominant renal artery is possible in the case of aberrant or accessory renal arteries [35]. However, there may be less of a blood pressure reduction in these patients [36].

Ablation is performed sequentially on both sides under repetitive DSA control using a high-frequency alternating current that is applied via electrodes at the catheter tip. As a result, there is local heating of the vascular wall to $45-70^{\circ} \mathrm{C}$ of causing thermal damage to the sympathetic nerve fibers in the vessel adventitia. The geometric arrangement of the ablation sites ( $\bullet$ Fig. 1 ) depends on the system used. De- pending on the system being used, there is no cooling, intraluminal cooling by blood flow, and/or by additional rinsing with heparinized salt solution via the guiding sheath. The ablation duration and the maximum energy output also differ depending on the system ( $\bullet$ Table 1 ).

Immediately after ablation, intramural edema can occur at the ablation sites ( $\bullet$ Fig.5). However, this is not flowlimiting and often can no longer be detected on final angiography.

During the intervention, systemic anticoagulation (activated clotting time (ACT) between $200-250$ s) is necessary in addition to the above-mentioned rinsing of the catheter system. In total, the intervention takes approx. 30-45 minutes depending on the system. Since the C-fibers (conducting pain) run together with the sympathetic nerve fi- 

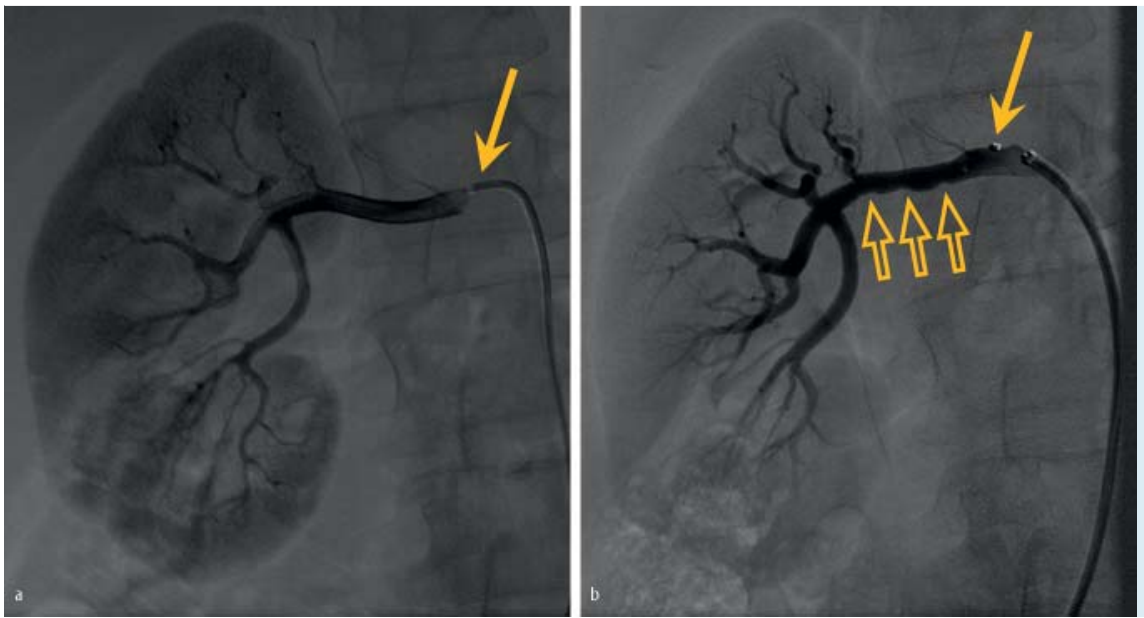

Fig. 5 a Digital subtraction angiography (DSA) of the right renal artery prior to renal denervation. Arrow: $5 \mathrm{~F}$-Cobra-II catheter used for intubation of the renal artery ostium. b Follow-up DSA after renal denervation. Open arrows: Intramural edema due to thermal damage caused by renal denervation.

bers, the ablation procedure is painful and deep analgesia is typically required. The pain ceases immediately after ablation. Analgesia should be performed according to the relevant guidelines [37]. Following renal denervation, thrombocyte aggregation inhibition (typically with ASS $100 \mathrm{mg} /$ $\mathrm{d}$ for 4 weeks) is recommended.

\section{Study results \\ $\nabla$}

\section{Blood pressure reduction}

The non-randomized cohort study Symplicity Hypertension (HTN)-1 was intended to prove the effectiveness and safety of renal denervation as a proof-of-concept study [30]. In this first study, renal denervation was performed in 45 patients with treatment-resistant hypertension. Despite treatment with an average of 4.7 antihypertensive medications, the average blood pressure prior to renal denervation was $177 / 101 \mathrm{mmHg}$. In the follow-up period of 12 months, there was a significant reduction of mean office blood pressure of $14 / 10 \mathrm{mmHg}$ (after 1 month), 21/10 $\mathrm{mmHg}$ (after 3 months), $22 / 11 \mathrm{mmHg}$ (after 6 months), 24/11 mmHg (after 9 months), and 27/17 mmHg (after 12 months, $\mathrm{p}=0.026$ ). To determine the renal sympathetic nervous system activity in 10 patients, the renal noradrenaline spillover rate was additionally determined. Continuous infusion with adrenaline marked with radioactive tritium is performed and the extraction rate is calculated from the difference between the renoarterial and renovenous concentration [14, 38]. The noradrenaline spillover rate decreased after renal denervation on average by $47 \%$ and correlated with the blood pressure reduction of $22 / 10 \mathrm{mmHg}$ after 6 months. However, the initial hypothesis that renal denervation generally results in systemic lowering of the sympathetic nervous system activity could not be confirmed in another study [39].

106 patients with treatment-resistant hypertension were included in the randomized Symplicity HTN-2 study between June 2009 and January 2010 [33]. Systolic blood pressure values of $\geq 160 \mathrm{mmHg}$ or $\geq 150 \mathrm{mmHg}$ had to be regularly present in patients with type 2 diabetes. At the start of the study, the average blood pressure values were $178 / 96 \mathrm{mmHg}$ prior to randomization despite the intake of an average of 5.2 antihypertensive medications. 1:1 randomization into a treatment group (intervention) and a con- trol group (continuation of treatment with medication) was then performed. Six months after renal denervation, the blood pressure in the control group was unchanged but had decreased in the patient group having undergone renal denervation by an average of $32 / 12 \mathrm{mmHg}(\mathrm{p}<0.0001)$. However, only a lower blood pressure reduction of 11 / $7 \mathrm{mmHg}$ compared to the control group was seen in the 20 patients of the HTN-2 study in whom an ambulatory blood pressure measurement was performed. 46 patients with treatment-resistant hypertension were treated in the prospective uncontrolled EnligHTN I study [40]. After 6 months a reduction of the systolic blood pressure of more than $10 \mathrm{mmHg}$ (average $26 \mathrm{mmHg}$ ) and of the diastolic blood pressure of an average of $10 \mathrm{mmHg}$ was seen in $76 \%$ of the patients. $33 \%$ of the patients reached the target blood pressure range of $<140 \mathrm{mmHg}$ [40]. After renal denervation with the Paradise system (ReCor Medical) in which denervation is performed via ultrasound ablation instead of radiofrequency ablation, lowering of the office blood pressure by $36 / 17 \mathrm{mmHg}$ or $22 / 12 \mathrm{mmHg}$ in the ambulatory blood pressure measurement was observed after 3 months [41].

In addition to these industry-initiated studies, data from smaller studies that were able to confirm the above results only partially or not at all have since been presented. In the above-mentioned study by Brinkmann et al., neither blood pressure lowering nor a change in the sympathetic nervous system activity could be documented [39]. In a second study, the influence on the 24-hour blood pressure profile was significantly lower than the effect of the office blood pressure values [42]. Furthermore, renal denervation seemed to have a smaller effect on the prognostically important ambulatory blood pressure measurements [43] than on the office blood pressure measurements [42-44]. For example, the office blood pressure values decreased on average by $\approx 30 / 15 \mathrm{mmHg}$ while the ambulatory blood pressure values only decreased by $23 / 10 \mathrm{mmHg}$ [42]. In another smaller study including 11 patients, only the office blood pressure decreased ( $189 \pm 23 / 92 \pm 15$ vs. $158 \pm 24 / 88$ $\pm 17 \mathrm{mmHg}, \mathrm{p}>0.05$ ), while the blood pressure of the 24hour measurement did not change (149 $\pm 19 / 82 \pm 17$ vs. $142 \pm 18 / 79 \pm 15 \mathrm{mmHg}, \mathrm{p}>0.05$ ) [45].

This difference in blood pressure reduction between office measurements and ambulatory blood pressure measure- 
ments is already known from pharmacological studies. A current meta-analysis was able to show that the office blood pressure was significantly lower (by $5.6 \mathrm{mmHg}$ ) than ambulatory blood pressure measurements in unblinded/ non-randomized pharmacological studies. This difference can no longer be detected after blinding and randomization [46]. The authors therefore predict that the blood pressure reduction due to renal denervation could be in the order of magnitude of $10-15 \mathrm{mmHg}$ [46]. In a first analysis of the scarce data, no statistically significant difference regarding the frequency of cardiovascular events could be shown between patients treated by renal denervation and the control group treated with medication [33].

As a result of the recently published data of the HTN-3 study [47], which was the first controlled and randomized study with a blinded control group, a new evaluation of renal denervation as a treatment option needs to be performed. In this study a total of 535 patients were randomized in a ratio of 2:1 into a denervation group and a control group [47-49]. The patients in the control group underwent a sham intervention under deep sedation so that these data allow the evaluation of effectiveness and riskbenefit ratio in particular in comparison to optimum treatment with medication and under minimization of methodological and statistical error sources [49]. The primary end point was the change in the office blood pressure after 6 months and the secondary end points were changes in the 24-hour blood pressure measurement and the safety of renal denervation [49].

However, the primary and secondary effectiveness end points ( $\bullet$ Fig.6) were not reached [47]. The systolic office blood pressure decreased by $14.1 \pm 23.9 \mathrm{mmHg}$ in the denervation group and by $11.7 \pm 25.9 \mathrm{mmHg}$ in the control group $(p<0.001)$ with the group difference being $2.4 \mathrm{mmHg}$ (95\% confidence interval $-6.9 \mathrm{mmHg}-2.1 \mathrm{mmHg}, \mathrm{p}=0.26$ for a superiority with a margin of $5 \mathrm{mmHg}$ ). The 24-hour blood pressure decreased by $6.8 \pm 15.1 \mathrm{mmHg}$ in the denervation group and by $4.8 \pm 17.2 \mathrm{mmHg}$ in the control group with the group difference being $1.96 \mathrm{mmHg}$ (95\% confidence interval $-5.0 \mathrm{mmHg}-1.1 \mathrm{mmHg}, \mathrm{p}=0.98$ for a superiority with a margin of $2 \mathrm{mmHg}$ )). The current data of the worldwide Sympli- city Register with a reduction in the office blood pressure of $11.9 \mathrm{mmHg}$ and the 24-hour blood pressure of $7.9 \mathrm{mmHg}$ are also significantly below the previously published results [50].

There are multiple possible explanations for the discrepancy in the blood pressure reduction between the HTN-3 study and the register data on the one hand and earlier studies that used the Symplicity catheter system on the other hand: 1. Lack of a control group: In the earlier, nonrandomized studies $[40,51]$, the treatment results were compared to the initial, baseline blood pressure values of the same patient and not to a control group resulting in a false evaluation of the effectiveness of the treatment. 2. Regression to mean effect: Higher blood pressure values on the day of study inclusion that facilitate or allow study inclusion are compared to "true" lower control values during follow-up [52]. This can also lead to an incorrectly good evaluation of treatment effectiveness. 3. Better medication compliance: Without a control group, the observed blood pressure reduction can be partially attributed to better intake of medication as a result, for example, of regular study follow-up (Hawthorne effect) [53]. 4. Detection bias and placebo effect: In the case of a lack of blinding, a therapeutic effect, i. e., blood pressure lowering, is expected. A possible placebo effect is then incorrectly attributed to the treatment [54].

The 3-year follow-up data of the HTN-1 study population that suggest that the achieved blood pressure reduction seems to be lasting must be reevaluated in the light of the HTN-3 study results [55]. The average systolic/diastolic blood pressure reduction was $26.5 \pm 21.5 / 13.5 \pm 14.1 \mathrm{mmHg}$ $(\mathrm{n}=123$ patients) after 12 months, 28.9 $\pm 23.5 / 14.0$ $\pm 15.2 \mathrm{mmHg}(\mathrm{n}=105$ patients $)$ after 24 months, and 32.0 $\pm 17.6 / 14.4 \pm 11.8 \mathrm{mmHg}(\mathrm{n}=88$ patients $)$ after 36 months ( $\odot$ Fig. 7), so that a long-lasting effect or even irreversibility of the thermal nerve fiber damage is assumed [56]. In addition to the fundamental concerns regarding the effectiveness of the treatment method, it is of note that in contrast to the data from an earlier publication [33] the number of antihypertensive medications could not be reduced (5.0 \pm 1.7 vs. $5.2 \pm 1.7)[55]$.

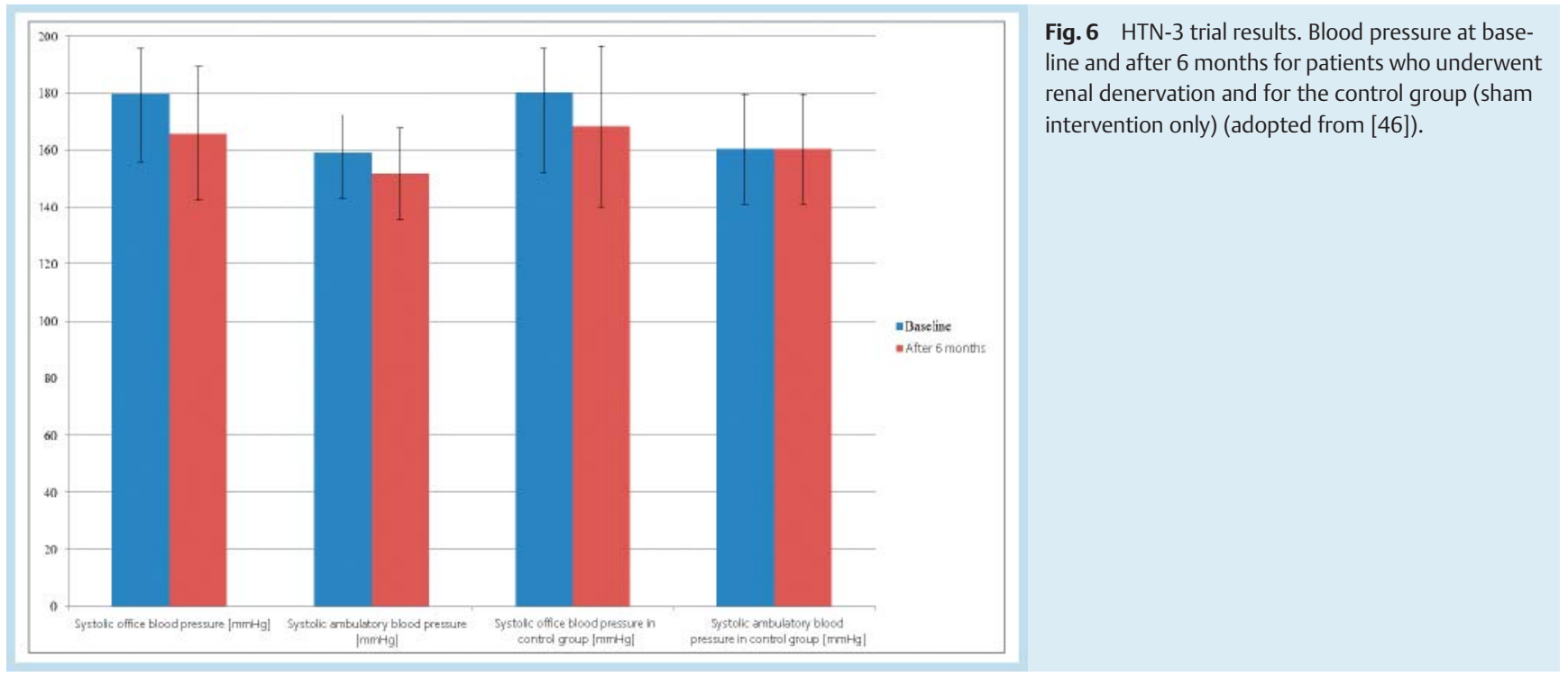




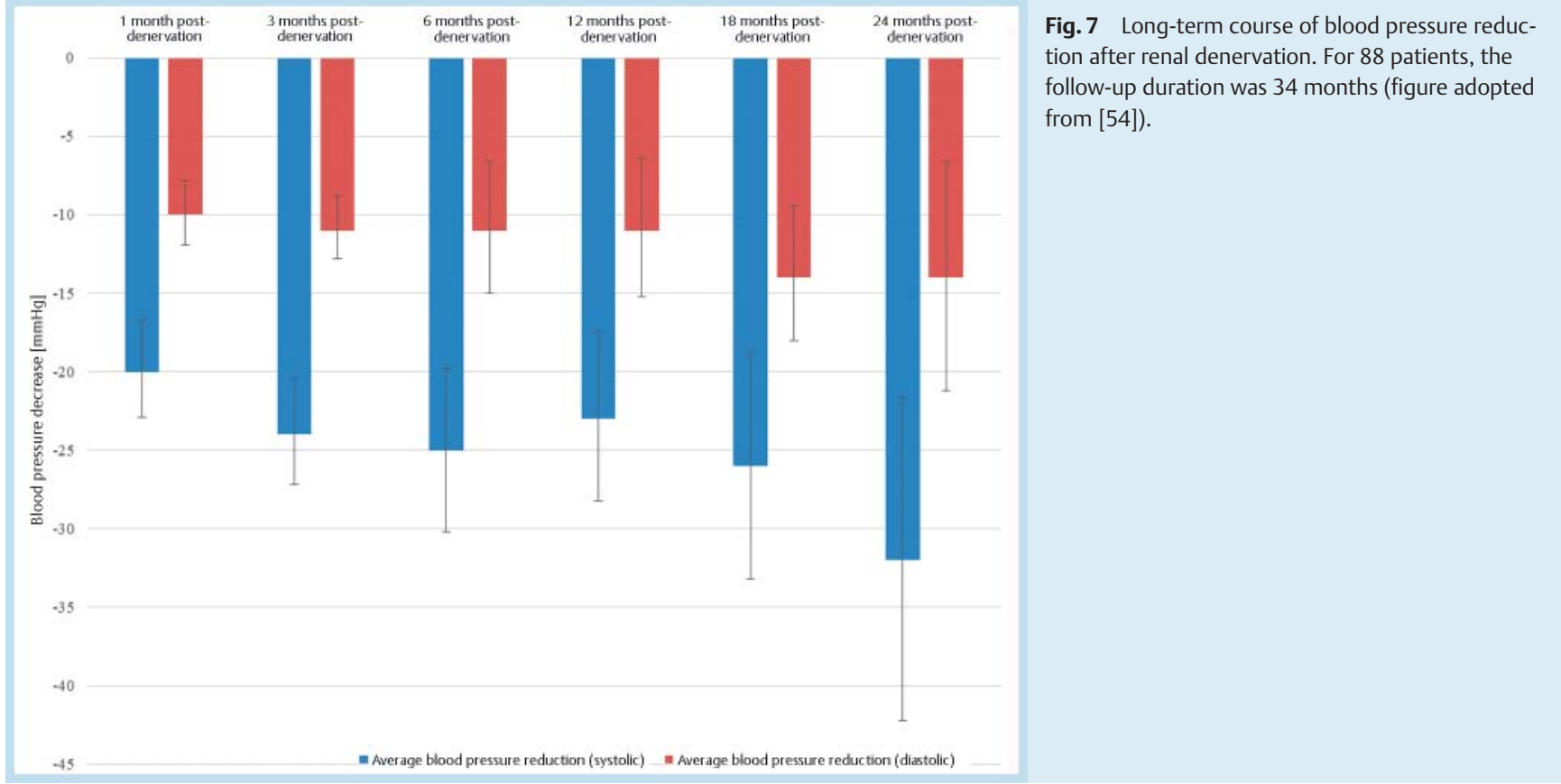

The previously reported response rate (treatment response=lowering of the systolic blood pressure in the office measurement of $>10 \mathrm{mmHg}$ ) of $84-92 \%$ in the Symplicity HTN-1 and Symplicity HTN-2 study [30,33] must also be reevaluated in light of the HTN-3 study. Using surgical sympathectomy a significant blood pressure reduction could only be achieved in $\approx 66 \%$ of patients [15]. However, a systolic blood pressure reduction of $20 \mathrm{mmHg}$ had to be achieved for treatment response. Using surgical sympathectomy the blood pressure reduction lasted for the entire follow-up period that was up to 13 years [15]. The results of other non-industry-initiated studies also show lower response rates of e.g. $25.6 \%$ in 39 patients [57]. The first long-term follow-ups indicated that the percentage of non-responders decreases with increasing time since denervation [55]. For instance, the percentage of non-responders among the HTN-1 participants was $31 \%$ after 1 month and $7 \%$ after 36 months. Finally, the pathophysiological causes of a lack of response or a quick or delayed response in these studies remain unclear, so that additional studies, e. g. follow-up studies with determination of the noradrenaline spillover rate.

The results of the HTN-3 study also raise questions as to which parameters are predictive for treatment response and may allow better patient selection. Smaller studies to date have shown that a high systolic blood pressure at the time of intervention $(\mathrm{p}<0.001)$, the intake of centrally acting sympatholytic agents $(\mathrm{p}=0.018)$, and a low heart rate $(p<0.004)$ could be independent predictors for treatment response [30,33]. Ablation characteristics such as the number of ablation points and the average ablation temperature also seem to affect treatment response [57]. For example, the blood pressure decreased by an average of $31.7 /$ $11.2 \mathrm{mmHg}$ in patients in whom an average of $15.5 \pm 2.9 \mathrm{ab}-$ lation sites were applied while this value was only 15.4 / $3.4 \mathrm{mmHg}$ in the case of $10.3 \pm 1.3$ ablation sites $(\mathrm{p}<0.01)$. A similar trend was seen for the average ablation tempera- ture (temperature - blood pressure lowering: $61.4 \pm 2.2^{\circ} \mathrm{C}-$ $43 / 20.4 \mathrm{mmHg}$ vs. $56.4 \pm 1.5{ }^{\circ} \mathrm{C}-28.5 / 7.4 \mathrm{mmHg}, \mathrm{p}<0.01$ ). However, due to the overall low non-responder rate in studies to date, predictors for a lack of treatment response could not yet be determined. In a recently published subgroup analysis, a trend in favor of the effectiveness of renal denervation in Caucasians in contrast to African Americans was seen even if statistical significance was not reached [58]. Since the percentage of African American patients was lower in earlier studies, this changed composition of the study population may have partially contributed to the negative outcome of the HTN-3 study. The extent to which these and other subgroup analyses of the HTN-3 data allow additional conclusionsmust be awaited.

\section{Additional effects of renal denervation.}

In addition to the blood pressure-lowering effect, focus is increasingly being placed on changes of other sympathetically innervated organs or organ functions. In addition to the blood pressure reduction, an improvement of the hyperinsulinism and insulin resistance present in metabolic syndrome seems to occur: 3 months after renal denervation the fasting glucose level ( $118 \pm 3.4$ vs. $108 \pm 3.8 \mathrm{mg} / \mathrm{dL})$, the insulin level $(20.8 \pm 3.0$ vs. $9.3 \pm 2.5 \mu \mathrm{IU} / \mathrm{mL})$ and the (calculated HOMA) insulin resistance decreased significantly [59]. However, these study populations were relatively small collective and not fully randomized $[59,60]$. Also a decrease of left ventricular hypertrophy (decrease in left ventricular mass index $6.3 \pm 2.2$ to $9.6 \pm 1.9 \mathrm{~g} / \mathrm{m}^{2.7}$ ) and an improvement in the left ventricular diastolic function were described [61] even though this study also has methodological weaknesses (including a lack of data regarding changes in antihypertensive medication in the follow-up period, echocardiography instead of the gold standard of cardiac MRI for determining the left ventricular mass) [62]. 
In a quality of life analysis, $75 \%$ of patients indicated feeling "much better" and $21 \%$ felt "better". $4 \%$ indicated no change in quality of life [63].

Studies to date have excluded patients with chronic renal diseases (GRF $<45 \mathrm{ml} / \mathrm{min} / 1.73 \mathrm{~m}^{2}$ ) even though renal denervation seems theoretically/physiologically benefitial in these patients since limited renal function can be associated with sustained sympathetic nervous system activation [19]. This hypothesis was tested in 15 patients with chronic renal insufficiency $3^{\circ}-4^{\circ}$ (mean estimated glomerular filtration rate (eGFR) $31 \mathrm{ml} / \mathrm{min} / 1.73 \mathrm{~m}^{2}$ ) with $\mathrm{CO} 2$ angiography being performed in 6 patients [64]. In addition to a reduction of the systolic and diastolic blood pressure (mean reduction of office blood pressure of $34 / 14 \mathrm{mmHg}$ after 1 month, of $25 / 11 \mathrm{mmHg}$ after 3 months, of $32 / 15 \mathrm{mmHg}$ after 6 months and of $33 / 19 \mathrm{mmHg}$ after 12 months), the physiological circadian rhythm with nightly blood pressure reduction was additionally restored. Renal function and retention parameters (eGFR, cystatin C, urea) as well as the renal plasma flow did not show any significant changes [64]. However, there are currently no clinical studies with larger numbers of patients proving this influence on the circadian blood pressure regulation in patients with renal insufficiency. Since there is a risk of further worsening of renal function in these patients as a result of contrast-induced nephropathy or acute renal failure due to interventionassociated cholesterol embolism [65, 66], patients with chronic renal diseases and a GFR $<45 \mathrm{ml} / \mathrm{min} / 1,73 \mathrm{~m}^{2}$ should currently not be treated with renal denervation outside of controlled studies.

\section{Side effects, complications}

The authors of previous studies consider the safety of renal denervation proven regardless of the catheter system used. However, direct periprocedural complications and a possible worsening of renal function should be reviewed separately.

In the three largest studies published before the HTN-3 study, a total of 305 patients were treated and followed-up $[33,40,55]$. New or progressive renal artery stenosis occurred in $6 / 305$ (2.0\%) patients, renal artery dissection occurred in $1 / 305(0.3 \%)$ patients, complications in the region of the access path such as hematomas or aneurysms occurred in $12 / 305$ (3.9\%) patients, and intraprocedural bradycardia occurred in $17 / 305(5.6 \%)$ patients $[30,33,56]$. This seems to be an acute effect of ablation since the blood pressure regulation and the chronotropic competence are retained after renal denervation [67]. Outside of these studies, de-novo renal artery stenosis developed in one patient [68], and preexisting renal artery stenosis progressed in another patient during the follow-up period [68]. However, it must be critically noted here that the limited follow-up interval and particularly the follow-up methodology are not suitable to detect slowly progressing changes in vascular wall morphology. Although imaging was performed in the HTN-2 study after 6 months in 43 (87\%) patients, CT or MRI was performed in only 10 (23\%) patients while the remaining patients underwent merely an ultrasound examination [33]. In the long-term follow-up of all patients treated in the HTN-1 and HTN-2 studies, imaging follow-up (CT, MRI, or ultrasound) was only available in $53 \%$ of the patients. In a porcine animal model, no inflammation was found at the ablation sites after 6 months, but instead increased fibrosis of the middle coat of the vessel [70] that does not contain any sympathetic nerve fibers and thus is not the primary target region of ablation.

The safety of renal denervation was also evaluated in the HTN-3 study. There were $5(1.4 \%)$ major complications in the denervation group vs. 1 (0.6\%) complication in the control group $(\mathrm{p}=0.67)$. Major complications were a combined end point of death for any reason, renal failure $\mathrm{IV}^{\circ}$, embolic end organ damage, vascular complication, hypertensive crisis $<30$ days after denervation and de-novo renal artery stenosis $>70 \%$ within 6 months after denervation. The authors conclude that renal denervation is a safe treatment procedure.

This conclusion may seem correct but a "fair" comparison is needed here. If the typical denervation-associated complications (newly occurring renal insufficiency, increase in serum creatinine $>50 \%$, embolic end organ damage, vascular complication requiring treatment, de-novo renal artery stenosis $>70 \%$ - that are representative for the safety of the intervention - are taken into consideration, there were $8(2.2 \%)$ complications in the denervation group and $1(0.6 \%)$ complication in the control group. Even if no statistical significance is achieved here due to the low number of events in both groups, the relative complication risk is 3.85 to the disadvantage of renal denervation. The access path complication rate of $0.3 \%$ specified by the authors is very low and may be able to be attributed to the special care used for study patients. For use in the clinical routine it must be assumed that the average complication rate will correspond with the typical average complication rate of $1.3 \%[71]$.

As in the HNT-1 and HTN-2 trial, the follow-up methodology for detecting renal artery stenoses again is problematic since only Doppler ultrasound was performed to detect renal artery stenoses [50]. Doppler ultrasound has a significantly lower sensitivity and specificity compared to CT and MR angiography [72, 73]. The extent to which this result would change in the case of corresponding follow-up via MR or CT angiography is currently speculative.

To date, there has not been significant or clinically relevant worsening of renal function within a year of renal denervation that was to be attributed to renal denervation [33]. Minimal worsening of the GFR (from $87 \pm 19 \mathrm{ml} / \mathrm{min} /$ $1.73 \mathrm{~m}^{2}$ to $82 \pm 20 \mathrm{ml} / \mathrm{min} / 1.73 \mathrm{~m}^{2}$ ) occurred in only one study [41]. Significant worsening was not seen in the denervation group or in the control group even in the HTN-3 study in which the renal function was determined by the serum creatinine, cystatin $C$ and estimated GFR. This is notable since on average twice the contrast agent volume was used in the denervation group compared to the control group (177.0 $\pm 76.6 \mathrm{ml}$ vs. $78.6 \pm 51.9 \mathrm{ml})$ [47] .

\section{Patient selection}

Only patients whose systolic blood pressure values were regularly over $160 \mathrm{mmHg}$ despite of receiving 3 or more antihypertensive medications were included in the Symplicity HTN-1, Symplicity-HTN-2 and EnligHTN studies. However, the average blood pressure in the Symplicity HTN-2 study was $180 / 100 \mathrm{mmHg}$ under treatment with an average of 5.2 antihypertensive medications. These limits differ from the current definition of treatment-resistant hypertension 
( $>140 \mathrm{mmHg}$ under $\geq 3$ antihypertensive medications) [2, 73]. In a first study including 54 patients with moderate hypertension $(\geq 140 / 90 \mathrm{mmHg}$ and $<160 / 100 \mathrm{mmHg}$ under treatment with an average of $5.1 \pm 1.4$ antihypertensive medications), the blood pressure decreased by an average of $13 / 7 \mathrm{mmHg}$ following renal denervation [75]. The blood pressure reduction was thus significantly less than in the originally defined patient population of the HTN-1 and HTN-2 studies. This coincides with pharmacological studies in which the extent of the blood pressure reduction correlates with the preinterventional blood pressure level [33].

\section{Outlook \\ $\nabla$}

Although the principle treatment approach of renal denervation is plausible on the basis of historic data, results from animal experiments $[17,26]$ and human studies $[15,19]$, the HTN-3 study as the first controlled, randomized, and blinded study after the initial positive study results $[33,40$, 51] provided sobering information with respect to blood pressure reduction by renal denervation being superior to optimal treatment with medication [47]. If this is the end of renal denervation for treatment-resistant hypertension currently cannot be predicted. In addition to effectiveness, the safety of the method plays an important role in the future of renal denervation. Relevant complications seem to be rare although weaknesses in the follow-up must be taken into consideration [47].

With regard to the blood pressure reduction and response rate to be achieved - particularly also in light of the discrepancy between the results of the HTN-3 study and previous studies with the above-mentioned flaws in study design, more realistic expectations seem appropriate. The Symplicity catheter system used in the HTN-3 study requires manual placement of the ablation sites in a helical configuration with a deviation from the ideal geometry possibly affecting the percentage of ablated nerves and thus affecting the treatment effect. In this regard systems with a predefined geometry of ablation sites may possibly be "more robust" with respect to blood pressure lowering. However, it is astonishing that a manufacturer of such a system announced its withdrawal from this market without giving a reason [34]. The influence of ablation geometry, i.e. position and density of ablation sites, should be examined in future studies.

Regarding the clinical use of renal denervation, strict compliance with the interdisciplinary guidelines must be ensured. Currently, renal denervation should only be used in controlled studies and Clinical routine use cannot be recommended on the basis of the available data. In the future, studies with hard morbidity and mortality end points are required in addition to studies re-examining the effectiveness of renal denervation.

\section{Summary}

\section{$\checkmark$}

Renal denervation is a novel, minimally invasive, catheterbased treatment option that could be of clinical use for a series of indications. The best examined indication to date for this novel method is treatment-resistant hypertension.
Previously available data showed extraordinary effectiveness for this indication with respect to blood pressure lowering and other parameters. However, the current results of the first controlled randomized and blinded study could not show sufficient superiority of renal denervation plus optimum treatment with medication compared to optimum treatment with medication alone [47]. Since the indications and contraindications for renal denervation were developed in an interdisciplinary manner based on initial study results [12], an update of the guidelines and a reevaluation of the method under consideration of the HTN-3 data are required. Until that time, the more or less routine clinical use of renal artery denervation as used in treatment-resistant hypertension in Germany should be suspended. At this time is cannot be ruled out that "treatment-resistant hypertension" will represent only a limited indication or no indication at all for this interventional procedure in the future. The analysis of the HTN-3 study data may help to identify subgroups of treatment-resistant patients for whom renal denervation can be useful in the future - in clinical studiesand possibly with other ablation systems. Other indications such as sleep apnea syndrome and insulin resistance should remain the object of clinical research.

\section{Literatur}

1 Wolf-Maier K, Cooper RS, Kramer H et al. Hypertension treatment and control in five European countries, Canada, and the United States. Hypertension 2004; 43: 10-17

2 Mancia G, Fagard R, Narkiewicz K et al. 2013 ESH/ESC Guidelines for the management of arterial hypertension: the Task Force for the management of arterial hypertension of the European Society of Hypertension (ESH) and of the European Society of Cardiology (ESC). J Hypertens 2013; 31: $1281-1357$

3 Düsing R. Aktuelle Aspekte der Kombinationstherapie bei Hypertonie. Kardiologe 2010; 4: 27-36

4 Lewington S, Clarke R, Qizilbash $N$ et al. Age-specific relevance of usual blood pressure to vascular mortality: a meta-analysis of individual data for one million adults in 61 prospective studies. Lancet 2002; 360: $1903-1913$

5 Calhoun DA, Jones D, Textor $S$ et al. Resistant hypertension: diagnosis, evaluation, and treatment. A scientific statement from the American Heart Association Professional Education Committee of the Council for High Blood Pressure Research. Hypertension 2008; 51: 1403-1419

6 de la Sierra A, Segura J, Banegas JR et al. Clinical features of 8295 patients with resistant hypertension classified on the basis of ambulatory blood pressure monitoring. Hypertension 2011; 57: 898 - 902

7 Tomaszewski M, White C, Patel P et al. High rates of non-adherence to antihypertensive treatment revealed by high-performance liquid chromatography-tandem mass spectrometry (HP LC-MS/MS) urine analysis. Heart 2014; DOI: 10.1136/heartjnl-2013-305063

8 Hayek SS, Abdou MH, Demoss BD et al. Prevalence of resistant hypertension and eligibility for catheter-based renal denervation in hypertensive outpatients. Am J Hypertens 2013; 26: $1452-1458$

9 Doumas M, Anyfanti P, Bakris G. Should ambulatory blood pressure monitoring be mandatory for future studies in resistant hypertension: a perspective. J Hypertens 2012; 30: 874-876

10 Dusing $R$. Therapietreue bei medikamentöser Behandlung. Deutsche medizinische Wochenschrift 2006; 131: H28-30

11 Jung 0 , Gechter JL, Wunder C et al. Resistant hypertension? Assessment of adherence by toxicological urine analysis. J Hypertens 2013; 31: $766-774$

12 Mahfoud F, Vonend O, Bruck H et al. Expert consensus statement on interventional renal sympathetic denervation for hypertension treatment. Deutsche medizinische Wochenschrift 2011; 136: 2418

13 Nahle $C P$, Schild $H$, Wilhelm $K$. Renal denervation: ready for prime time? Deutsche medizinische Wochenschrift 2013; 138: 2212-2218 
14 Esler M, Jennings $G$, Korner P et al. Assessment of human sympathetic nervous system activity from measurements of norepinephrine turnover. Hypertension 1988; 11: 3-20

15 Grimson KS, Orgain ES, Anderson B et al. Total thoracic and partial to total lumbar sympathectomy, splanchnicectomy and celiac ganglionectomy for hypertension. Ann Surg 1953; 138: 532 - 547

16 Campese VM, Kogosov E. Renal afferent denervation prevents hypertension in rats with chronic renal failure. Hypertension 1995; 25 : $878-882$

17 Ye S, Gamburd M, Mozayeni P et al. A limited renal injury may cause a permanent form of neurogenic hypertension. Am J Hypertens 1998; 11: $723-728$

18 Rump LC, Amann K, Orth S et al. Sympathetic overactivity in renal disease: a window to understand progression and cardiovascular complications of uraemia? Nephrol Dial Transplant 2000; 15: 1735 - 1738

19 Hausberg $M$, Kosch $M$, Harmelink P et al. Sympathetic nerve activity in end-stage renal disease. Circulation 2002; 106: 1974-1979

20 Barajas L, Liu L, Powers K. Anatomy of the renal innervation: intrarenal aspects and ganglia of origin. Can J Physiol Pharmacol 1992; 70: 735 749

21 Bertog SC, Sobotka PA, Sievert $H$. Renal denervation for hypertension. JACC Cardiovascular interventions 2012; 5: 249-258

22 DiBona GF. Physiology in perspective: The Wisdom of the Body. Neural control of the kidney. Am J Physiol Regul Integr Comp Physiol 2005; 289: R633-641

23 Michel MC, Rump LC. alpha-Adrenergic regulation of human renal function. Fundam Clin Pharmacol 1996; 10: 493-503

24 DiBona GF, Kopp UC. Neural control of renal function. Physiological reviews 1997; 77: 75-197

25 Mahfoud F, Bohm M. Interventional renal sympathetic denervation - a new approach for patients with resistant hypertension. Deutsche medizinische Wochenschrift 2010; 135: 2422-2425

26 Ye S, Zhong H, Yanamadala S et al. Oxidative stress mediates the stimulation of sympathetic nerve activity in the phenol renal injury model of hypertension. Hypertension 2006; 48: 309-315

27 Vonend O, Rump LC, Ritz E. Sympathetic overactivity - the Cinderella of cardiovascular risk factors in dialysis patients. Semin Dial 2008; 21: $326-330$

28 DiBona GF. Neural control of the kidney: past, present, and future. Hypertension 2003; 41: $621-624$

29 Krum H, Sobotka P, Mahfoud F et al. Device-based antihypertensive therapy: therapeutic modulation of the autonomic nervous system. Circulation 2011; 123: 209-215

30 Krum H, Schlaich M, Whitbourn R et al. Catheter-based renal sympathetic denervation for resistant hypertension: a multicentre safety and proof-of-principle cohort study. Lancet 2009; 373: 1275-1281

31 Hutchinson BD, Keane D, Dodd JD. Renal sympathetic denervation: MDCT evaluation of the renal arteries. Am J Roentgenol 2013; 201: W342-W346

32 Rosenbaum D, Rigabert J, Villeneuve F et al. An abdominal CT scan in first-line is an efficient investigation of uncontrolled hypertensives suspected to have an adrenal cause. Ann Cardiol Angeiol (Paris) 2012; 61: $209-212$

33 Esler MD, Krum H, Sobotka PA et al. Renal sympathetic denervation in patients with treatment-resistant hypertension (The Symplicity HTN2 Trial): a randomised controlled trial. Lancet 2010; 376: $1903-1909$

34 Covidien plc. Covidien to Exit OneShot ${ }^{\mathrm{TM}}$ Renal Denervation Program. In. Dublin, Ireland: 2014

35 Schmid A, Ditting T, Sobotka PA et al. Does renal artery supply indicate treatment success of renal denervation? Cardiovascular and interventional radiology 2013; 36: 987 -991

36 Id D, Kaltenbach B, Bertog SC et al. Does the presence of accessory renal arteries affect the efficacy of renal denervation? JACC Cardiovascular interventions 2013; 6: 1085-1091

37 Van Aken H, Biermann E, Martin J et al. Analgosedierung für diagnostische und therapeutische Maßnahmen bei Erwachsenen. Anästh Intensivmed 2010; 51: S598 - S602

38 Esler $M$. The sympathetic nervous system through the ages: from Thomas Willis to resistant hypertension. Experimental physiology 2011; 96: $611-622$

39 Brinkmann J, Heusser K, Schmidt BM et al. Catheter-based renal nerve ablation and centrally generated sympathetic activity in difficult-tocontrol hypertensive patients: prospective case series. Hypertension 2012; 60: 1485 - 1490
40 Worthley SG, Tsioufis CP, Worthley MI et al. Safety and efficacy of a multi-electrode renal sympathetic denervation system in resistant hypertension: the EnligHTN I trial. Eur Heart J 2013; 34: 2132 - 2140

41 Mabin T, Sapoval M, Cabane V et al. First experience with endovascular ultrasound renal denervation for the treatment of resistant hypertension. Eurolntervention 2012; 8: $57-61$

42 Mylotte D, Benamer $H$, Unterseeh $T$ et al. Percutaneous renal denervation for resistant hypertension: Real world outcomes. In: ACC. Chicago, USA J Am Coll Cardiol 2012: E1708

43 Clement DL, De Buyzere ML, De Bacquer DA et al. Prognostic value of ambulatorytb blood-pressure recordings in patients with treated hypertension. The New England journal of medicine 2003; 348: 2407 2415

44 Luetkens JA, Wilhelm K, Düsing $R$ et al. Renal Denervation: Results of a Single-Center Cohort Study. Fortschr Röntgenst 2014, [Epub ahead of print]

45 Zuern CS, Rizas KD, Eick C et al. Effects of Renal Sympathetic Denervation on 24-hour Blood Pressure Variability. Front Physiol 2012; 3: 134

46 Howard JP, Nowbar AN, Francis DP. Size of blood pressure reduction from renal denervation: insights from meta-analysis of antihypertensive drug trials of 4,121 patients with focus on trial design: the CONVERGE report. Heart 2013; 99: $1579-1587$

47 Bhatt DL, Kandzari DE, O'Neill WW et al. A controlled trial of renal denervation for resistant hypertension. The New England journal of medicine 2014; 370: 1393 - 1401

48 Black HR, Elliott WJ, Grandits G et al. Principal results of the Controlled Onset Verapamil Investigation of Cardiovascular End Points (CONVINCE) trial. JAMA 2003; 289: 2073-2082

49 Kandzari DE, Bhatt DL, Sobotka PA et al. Catheter-based renal denervation for resistant hypertension: rationale and design of the SYMPLICITY HTN-3 Trial. Clinical cardiology 2012; 35: 528-535

50 Medtronic. Six-Month Analysis of First 1,000 Patients Enrolled in RealWorld Patient Registry. In Minneapolis, USA: 2014

51 Schlaich MP, Sobotka PA, Krum H et al. Renal sympathetic-nerve ablation for uncontrolled hypertension. The New England journal of medicine 2009; 361: $932-934$

52 Barnett AG, van der Pols JC, Dobson AJ. Regression to the mean: what it is and how to deal with it. International journal of epidemiology 2005; 34: $215-220$

53 McCambridge J, Witton J, Elbourne DR. Systematic review of the Hawthorne effect: new concepts are needed to study research participation effects. Journal of clinical epidemiology 2014; 67: 267-277

54 Bakris GL, Lindholm LH, Black HR et al. Divergent results using clinic and ambulatory blood pressures: report of a darusentan-resistant hypertension trial. Hypertension 2010; 56: 824-830

55 Krum H, Schlaich MP, Bohm M et al. Percutaneous renal denervation in patients with treatment-resistant hypertension: final 3-year report of the Symplicity HTN-1 study. Lancet 2014; 383: 622-629

56 Symplicity HTN-1 Investigators. Catheter-based renal sympathetic denervation for resistant hypertension: durability of blood pressure reduction out to 24 months. Hypertension 2011; 57: 911 - 917

57 Blondin D, Gao X, Blum K et al. Einfluß der Ablationstemperatur und der Ablationsanzahl auf den Therapieerfolg der renalen Ablation. Deutscher Röntgenkogress 2013, Hamburg

58 Bakris GL, Townsend RR, Liu M et al. Impact of Renal Denervation on 24hour Ambulatory Blood Pressure: Results from SYMPLICITY HTN-3. J Am Coll Cardiol 2014; 64: 1071 - 1078

59 Mahfoud F, Schlaich M, Kindermann I et al. Effect of renal sympathetic denervation on glucose metabolism in patients with resistant hypertension: a pilot study. Circulation 2011; 123: 1940-1946

60 Persu A, Renkin J, Asayama K et al. Renal denervation in treatment-resistant hypertension: the need for restraint and more and better evidence. Expert review of cardiovascular therapy 2013; 11: 739-749

61 Schirmer SH, Sayed MM, Reil JC et al. Improvements of left-ventricular hypertrophy and diastolic function following renal denervation - Effects beyond blood pressure and heart rate reduction. I Am Coll Cardiol 2013; DOI: S0735-1097(13)06233-5 [pii] 10.1016/j.jacc.2013.10.073

62 Bakris G, Nathan S. Renal Denervation and Left Ventricular Mass Regression: A benefit beyond blood pressure reduction? J Am Coll Cardiol 2013; DOI: S0735-1097(13)06234-7 [pii] 10.1016/j.jacc.2013.11.015

63 Dorr O, Liebetrau C, Mollmann $H$ et al. Influence of renal sympathetic denervation on quality of life. J Interv Cardiol 2013; 26: 536-541

64 Hering $D$, Mahfoud $F$, Walton AS et al. Renal denervation in moderate to severe CKD. J Am Soc Nephrol 2012; 23: 1250 - 1257 
65 de Bie MK, van Rees JB, Herzog CA et al. How to reduce the incidence of contrast induced acute kidney injury after cardiac invasive procedures, a review and practical recommendations. Curr Med Res Opin 2011; 27: $1347-1357$

66 Scolari F, Ravani P. Atheroembolic renal disease. Lancet 2010; 375: $1650-1660$

67 Ukena C, Mahfoud F, Kindermann I et al. Cardiorespiratory response to exercise after renal sympathetic denervation in patients with resistant hypertension. J Am Coll Cardiol 2011; 58: 1176 - 1182

68 Vonend $O$, Antoch G, Rump LC et al. Secondary rise in blood pressure after renal denervation. Lancet 2012; 380: 778

69 Pucci G, Battista F, Lazzari L et al. Progression of Renal Artery Stenosis After Renal Denervation. Circulation journal: official journal of the Japanese Circulation Society 2014; 78: 767 - 768

70 Rippy MK, Zarins D, Barman NC et al. Catheter-based renal sympathetic denervation: chronic preclinical evidence for renal artery safety. Clin Res Cardiol 2011; 100: 1095 - 1101
71 Applegate RJ, Sacrinty MT, Kutcher MA et al. Trends in vascular complications after diagnostic cardiac catheterization and percutaneous coronary intervention via the femoral artery, 1998 to 2007. JACC Cardiovascular interventions 2008; 1 : 317-326

72 Leung DA, Hoffmann U, Pfammatter T et al. Magnetic resonance angiography versus duplex sonography for diagnosing renovascular disease. Hypertension 1999; 33: 726-731

73 Halpern EJ, Rutter CM, Gardiner GA et al. Comparison of Doppler US and CT angiography for evaluation of renal artery stenosis. Academic radiology 1998; 5: 524-532

74 Whitworth JA, Chalmers J. World health organisation-international society of hypertension (WHO/ISH) hypertension guidelines. Clin Exp Hypertens 2004; 26: 747-752

75 Ott C, Mahfoud F, Schmid A et al. Renal denervation in moderate treatment-resistant hypertension. J Am Coll Cardiol 2013; 62: 1880 - 1886 